\title{
LA INGENIERÍA CONSTITUCIONAL Y SUS LÍMITES*
}

\author{
GIOVANNI SARTORI \\ Emérito \\ Columbia University
}

¿Por qué utilizo la expresión "ingeniería constitucional"? La razón es que parto de un enfoque distinto del tradicional, que acostumbra a hablar mas bien de redacción o confección constitucional. A mi juicio, las constituciones no son meros documentos legales plagados de mandatos y prohibiciones que organizan el poder. También se espera de ellas que ordenen el comportamiento, es decir, que contengan incentivos, recompensas y factores disuasorios. Siendo como son las reglas del juego, nos vemos obligados a estimular y premiar a los participantes que lo hagan bien y a castigar el juego sucio y a los tramposos. Ademas, gran parte de mi trabajo gira en torno al análisis de las circunstancias, es decir, de la situación "de facto" en la que las constituciones existen y funcionan. Pero esto es algo que comprobaremos a medida que avancemos en la exposición.

El siguiente interrogante es ¿cuál es la finalidad, el "telos" de una constitución? En principio las constituciones son instrumentos de protección: su interés primordial radica en controlar y limitar el ejercicio del poder político. Como señalaba, de manera breve, la Declaración Francesa de Derechos de 1789 en su artículo 16 "Cualquier sociedad en la que la garantía de los derechos no esté asegurada, ni la separación de poderes establecida, carece de Constitución". Por lo tanto, desde 1789 ha quedado definitivamente sentado que las constituciones son necesarias -para permanecer fieles a su intención última- para proteger los derechos de los destinatarios del poder, de los ciudadanos. En cuanto al otro requisito, la idea de la separación de poderes, no debe entenderse de forma literal (como hicieron los autores de

* Versión española de Santiago Sánchiz GonZálfz. Profesor Titular de la UNED. 
la constitución de Estados Unidos en 1787), sino en el sentido de que a fin de limitar al poder debemos contar con un poder no concentrado. Así, la limitación del poder puede lograrse dividiéndolo o compartiéndolo, pues según ambas fórmulas el punto de partida es que ninguna persona sola ostente y controle todo el poder.

Sin embargo, las constituciones no son solamente instrumentos de protección; son también instrumentos de gobierno y, en la medida de lo posible (de manera compatible con el propósito de restringir el poder), de un gobierno eficaz. A este respecto, las constituciones son como las carreteras y las normas de tráfico: indican el itinerario, el camino que permite un ejercicio controlado del poder. Y si estas normas de tráfico conducen a un punto muerto o a un gobierno ineficaz y débil, entonces nos encontramos ante una constitución mal diseñada o, vulgarmente hablando, ante una mala constitución.

Así pues, estimo que si el término "constitución" se aplica a cualquiera y a todas las formas de gobierno (como sostiene el positivismo jurídico cuando argumenta que todo Estado tiene por definición una constitución), el constitucionalismo queda degradado. En mi opinion, la palabra "constitución" es aplicable únicamente a una forma de Estado que implica un cierta protección de los ciudadanos ${ }^{1}$, Pero una constitucion garantista también puede ser una mala constitución en términos operativos. No es fácil conseguir un equilibrio entre un gobierno controlado y un gobierno efectivo, entre un poder restringido y un poder eficaz. En las líneas que siguen me centraré en el análisis de ese equilibrio y en el aspecto de la gobernabilidad de la balanza.

Permítaseme entrar enseguida en materia afirmando que la forma de gobierno presidencialista, tal y como se ha adoptado en toda Latinoamérica al sur de Méjico, es una demostración de lo que son sistemas constitucionales mal diseñados. Aparte de Méjico - que es un caso peculiar-, el tipo norteamericano de presidencialismo ha creado con frecuencia presidentes débiles (generalmente paralizados), que superan sus frustraciones de gobierno excediéndose de sus competencias (mediante el decretismo y otros medios de dudosa legalidad). De esta forma, cuando los presidentes latinoamericanos han respetado la constitución, se han mostrado generalmente ineptos, y han fracasado en sus programas de reforma. Y cuando han sido "fuertes" han ignorado la constitución. De ahí ese patrón de regímenes constitucionales intermitentes, interrumpidos por golpes militares y tomas de poder. Por fortuna, eso ha dejado de ser la norma. Pero esto implica que los sistemas políticos latinoamericanos tengan que enfrentarse ahora a los problemas sin la "ayuda" de los generales, es decir, trabajando en el marco de las constituciones que tienen o, mejor aún, tratando de mejorarlas. ¿Cómo? A continuación lo veremos.

La ingeniería constitucional es en gran parte una labor extrajurídica. No se pretende con ella dejar de lado a los juristas constitucionales, sino buscar horizontes

1. Una opinión que defiendo apasionadamente en el Capítulo I dedicado a la constitución, en mi obra Elementos de teoria politica, Alianza Editorial, Madrid, 1992. 
más amplios. Si se me pidiera redactar una constitución, solicitaría inmediatamente la ayuda de expertos legales. Pero no ocurriría lo mismo si fueran los expertos en leyes los que fueran los encargados de hacer la constitución. Los constitucionalistas siempre han estado muy seguros de sí mismos y no les gusta, por así decirlo, aquello que se encuentra extra muros. Aun así, creo que, para escribir una constitución, el jurista necesita al científico de la política tanto como éste precisa de aquél. Y no se trata sólo de un asunto de competencias técnicas, sino de ámbito territorial, pues el territorio que debe cubrir la ingeniería constitucional se extiende mucho más allá del propio de un texto constitucional.

A título ilustrativo, tanto si los sistema electorales y los partidos políticos están formalmente incluidos en un documento constitucional como si no lo están, son en todo caso un ingrediente esencial de la trama constitucional y de cómo se conforman las constituciones. Una misma estructura organizativa funciona de manera muy distinta dependiendo de qué sistema electoral condiciona qué sistema de partidos. De manera que para el ingeniero constitucional el modo de votar y los partidos son un componente inevitable de su oficio y son los cimientos desde los que debe comenzar su trabajo.

En la democracias los sistemas electorales reclutan al personal político. Es dudoso que los sistemas electorales puedan por sí sólos afectar significativamente, en la actualidad, la selección de representantes "buenos" y de un liderazgo capaz 2 . Pero los sistemas electorales afectan con toda seguridad a la configuración de los sistemas de partidos, es decir, a su número (de partidos relevantes) y, por ende, a las propiedades sistémicas que acompañan a la mayor o menor fragmentación ${ }^{3}$. Además, los sistemas electorales pueden también favorecer a ciertos partidos (p.ej. los partidos de centro) y en última instancia afectar a su naturaleza. Sin embargo, ya que la influencia de los sistemas electorales será objeto central de mi examen, regresaré a este tópico más tarde. Por el momento, y en primer lugar, esbozaré el conjunto, el marco completo.

Respecto a los partidos políticos, mantengo firmemente -y más aun en tiempos de descrédito- que las democracias a gran escala no pueden funcionar sin la intermediación de los partidos. Lord Bryce escribió en 1921 que "nadie ha llegado a demostrar cómo podría funcionar el gobierno representativo sin los partidos " ${ }^{4} \mathrm{y}$ nadie lo ha demostrado hasta la fecha, setenta y cinco años después. Pero, volviendo a nuestro objeto de preocupación, hay que preguntarse: ¿que partido o qué aspecto del tópico partidista guarda relación con nuestra investigación?

Entre las diversas maneras de analizar a los partidos, la pertinente en esta discusión gira en torno a la división entre i) el partido parlamentario, ii) el partido electoral y iii) el partido colonizador. Este último, el omnívoro partido semejante

2. Discuto con detalle el valor selectivo de la elección mediante elecciones en el capítulo 6 , seccs. 3, 4 y 9 de mi Teoría de la democracia, Alianza Editorial, 1988, 1995.

3. La asociación entre el número de partidos y las propiedades sistémicas (funcionales) de los sistemas de partidos constituye el tema principal de mi Partidos y sistemas de partidos, Alianza Editorial, Madrid, 1980 (2. ${ }^{\text {a }}$ ed. ampliada de 1992 y 1994).

4. James Bryce, Modern democracies, MacMillan, 1921, vol. I, p. 119. 
a un pulpo, identificado a menudo bajo la denominación italiana de partitocracia (partidocracia), es una degeneración que puede dejarse a un lado como tal, como un caso de la patología de los partidos; porque ciertamente el partido colonizador omnipenetrante no es un elemento necesario de la democracia. Por lo tanto me ocuparé más bien de las otras dos clases.

El partido parlamentario, es decir, el partido en el parlamento, puede ser más o menos "Sólido", y su solidez -o, a la inversa, su volatilidad- está en función de su disciplina de voto tal y como se mide por el cruce de las líneas partidistas. Un grado bajo de disciplina de partido -como, p. ej., en los Estados Unidos- puede resultar útil en un sistema presidencial en el que el presidente no cuente con una mayoría en el Congreso (ya que permite que un presidente consiga los votos que necesita para que prosperen sus iniciativas legislativas). Pero un sistema parlamentario afectado por la indisciplina no puede permitírselo. Si un gobierno sostenido por el parlamento no puede confiar en una mayoría parlamentaria segura (relativamente segura), está condenado a la impotencia. De ahí que el cómo conseguir partidos parlamentarios disciplinados sea una de las preocupaciones principales de la ingeniería constitucional.

Desde esta óptica, nuestra atención se centra ahora en el partido electoral, en el partido-en-pos-de-los-votos. Porque ¿cómo se explica que un partido (su elite gobernante) adquiera el control y pueda imponer la disciplina sobre sus parlamentarios? La respuesta simple y terminante es: observa quién controla el dinero. Ser elegido cuesta -en casi todas partes- mucho dinero. ¿De dónde provienen los fondos? ¿Quién los recibe? Si van directamente a cada candidato, es decir, si cada uno de ellos puede, y logra, conseguir los recursos que le permiten triunfar en su distrito, está claro que los parlamentarios son bastante independientes del partido. $\mathrm{Si}$, en cambio, el dinero político se ingresa en el partido como entidad, y si el apoyo de la organización partidista resulta crucial para la elección, entonces es obvio que los parlamentarios dependen del partido en el sentido de que si uno de ellos causara problemas al partido porque no pudiera confiarse en él en las votaciones, pondría en peligro su re-elección -y el diputado en cuestión lo sabe-. Lo que sucede es que el partido controla a sus miembros hasta el punto de que tiene el poder de recompensarles (la reelección) y de castigarles, no incluyéndoles en sus listas.

Volviendo a la distinción entre los sistemas presidenciales y parlamentarios, no hay duda de que es la más importante de las realizadas desde una base constitucional entre las formas democráticas de gobierno. Y, sin embargo, se trata de una distinción demasiado simple e insuficiente. Nosotros precisamos de un marco más analítico y el que propongo a continuación distingue cinco casos y ofrece una tipología quíntuple. Es el siguiente:

1. Sistemas presidenciales (tipo Estados Unidos).

2. Sistemas semi-presidenciales (tipo Francia). 
3. Sistema de gabinete (tipo inglés).

4. Sistema de canciller (tipo alemán).

5. Sistema parlamentario normal (el de todas las comunidades políticas del occidente excluyendo a Francia y Alemania).

Es cierto que según la clasificación tradicional de los sistemas políticos mis tres últimos tipos pertenecen a la misma especie de sistemas parlamentarios. Pero así no captamos diferencias cruciales y no podemos dedicarnos a construir con garantías una buena clase de parlamentarismo. Lo que equivale a decir que nuestro problema es evitar el mal parlamentarismo, o sea, su variedad asamblearia.

Podemos ahora ya abordar el tema de la ingeniería constitucional; lo que me propongo hacer desde la perspectiva de la capacidad de gobierno de nuestras democracias. Así, la pregunta es ¿bajo qué condiciones puede cada uno de los sistemas mencionados funcionar adecuada y eficazmente?

1. Por lo que hace a los sistemas presidenciales, las condiciones óptimas son un gobierno unido (lo cual significa que las mayorías presidencial y parlamentaria son las mismas), y un sistema de dos o de pocos partidos que sean relativamente sólidos (disciplinados). No obstante, en condiciones adversas, es decir en el caso de un gobierno dividido en el que el presidente no cuente con là mayoría, los partidos indisciplinados se convierten la válvula de seguridad del presidencialismo.

2. En cuanto al semi-presidencialismo, los requisitos antes mencionados cambian, ya que este sistema también puede funcionar con un gobierno dividido y cuatro o cinco partidos. Pero el semipresidencialismo siempre funciona mejor con partidos políticos sólidos.

3. El sistema inglés de gabinete implica un principio de liderazgo (como una de las convenciones constitucionales), y está estrictamente condicionado por un gobierno de partido único que, a su vez, necesita de un sistema bipartidista y partidos altamente disciplinados. En condiciones distintas el sistema inglés pronto dejaría de funcionar.

4. Igualmente la democracia de canciller alemana presupone un principio de liderazgo, pero permite gobiernos de coalición y más de dos partidos. Aun así podría tener dificultades con un sistema de más de cuatro partidos, sobre todo si poseen una fuerza semejante.

5. Por último, el funcionamiento de los sistemas parlamentarios depende casi en su totalidad, y de manera crucial, de la naturaleza del sistema de partidos. El gobierno de un solo partido (que corresponde al sistema de partido predominante, como yo lo califico) se ha dado durante periodos relativamente prolongados en Noruega, Suecia, Japón y, recientemente, en España entre 1982 y 1986; y ésta, es desde, luego una condición óptima para gobernar. Pero también pueden funcionar gobiernos de coalición con tal de que la coalición gobernante sea homogenea y relativamente fundible; y esto está en buena medida en función del sistema de partidos.

En todos los casos descritos la idea subyacente es que si no se dan las condiciones que cada sistema requiere o presupone, el sistema en cuestión fallará y no funcionará como se pretendía. Y la nota destacable de toda la argumentación es que en todas las instancias el factor dominante resulta ser el sistema de partidos y, por ende, la base partidista del gobierno. De ahí que la cuestión fundamental sea: 
¿qué es lo que conforma el sistema de partidos? Conocemos la respuesta en la medida en que sea posible diseñar un sistema de partidos, a saber, que el sistema electoral configura el sistema de partidos y puede cambiarlo. Por lo tanto, nuestra pregunta puede formularse en los siguientes términos: ¿hasta qué punto los sistemas electorales pueden producir el sistema de partidos apropiado, el sistema que cada una de nuestras formas de gobierno demanda?

La pregunta no pretende de ninguna manera disminuir la importancia que tienen por sí mismas la normas constitucionales. Por ejemplo, el artículo 67 de la Ley Fundamental que regula la moción de censura constructiva, que establece que la Dieta Federal sólo podrá expresar su desconfianza frente al Canciller si al mismo tiempo elige por la mayoría de sus miembros a un sucesor, ha sido muy útil para los alemanes. De igual forma, el artículo 40 de la Constitución francesa de 1958, que impide cualquier recorte presupuestario propuesto por los miembros del parlamento, ha servido cumplidamente a la quinta República Francesa. Está claro que de poco sirve un buen sistema de partidos con una constitución mala. Pero una buena constitución puede no servir de mucho si se ve minada por un mal sistema de partidos. A mi juicio, la difamada Constitución de Weimar fue brillantemente concebida para su tiempo; funcionó de manera deficiente debido a un sistema de partidos muy polarizado y demasiado fragmentado que era, a su vez, el producto de la representación proporcional -un sistema electoral definitivamente erróneo en aquellas circunstancias.

Una vez explicada la entrada de los partidos en la discusión, volvamos a la pregunta sobre el cómo y hasta qué punto es posible diseñar un sistema de partidos. Esta es la pregunta que trae a colación el papel y la influencia de los sistemas electorales.

Desde hace tiempo vengo sosteniendo que los sistemas electorales son los instrumentos más manipulables de la vida política. Por la misma razón, la ingeniería constitucional comienza aquí. Los sistemas electorales convierten los votos en escaños de maneras muy diversas, y ya he explicado en detalle en otras obras cómo facilitan la reducción o la multiplicación del número de partidos, determinando así la naturaleza del sistema, su funcionamiento sistémico (lo que denomino su mecánica) y también, en alguna medida, la naturaleza de los partidos per se $e^{5}$.

El saber común, tal y como fue expresado originariamente (en 1950 y 1951) por las "leyes" de Duverger relativas a la influencia de los sistemas electorales, se resume en: 1) el sistema mayoritario a una sola vuelta tiende a producir un bipartidismo; y 2) los sistemas de representación proporcional multiplican el número de partidos y conducen al multipartidismo. Pero esto resulta demasiado simple, demasiado impreciso y a menudo equivocado. Equivocado porque Duverger no advirtió la condición previa según la cual los sistemas electorales no ejercen influencia hasta que el sistema de partidos está estructurado; quiero decir, si los partidos no son tales (sino meras siglas) y si no existe un sistema de partidos verdadero. Por ejemplo, en el contexto político de los notables, o del caciquismo, es

5. Véase en particular mi obra Ingeniería constitucional comparada, Fondo de Cultura, México, 1995, capítulos 3 y 4 . 
bastante obvio que el sistema electoral carece de efecto alguno, puesto que los mismos notables y los jefes de la maquinaria electoral serán elegidos con independencia del sistema de votación que se adopte.

Sea lo que fuere, siguiendo la pauta del enfoque de Duverger, he inferido un conjunto detallado de "leyes" que no voy a reproducir aquít. Porque aquí debo centrarme en los límites de la ingeniería constitucional, y ello me permite reconsiderar mis reflexiones sobre lo que los sistemas electorales no pueden bacer.

Limitemos el problema a esta única y principal preocupación: ¿cómo es posible reducir, o mantener a niveles bajos, el número de partidos, incluso al mínimo de dos partidos (ciertamente, dos partidos relevantes)? En esta materia la creencia general es que las elecciones mayoritarias, es decir, el sistema inglés de circunscripciones uninominales, o crea al sistema bipartidista o lo mantiene. Y así es, pero también, y aun con mayor frecuencia, no.

Para empezar estamos aquí ante dos supuestos muy diferentes.

En un caso decimos "mantener", lo que significa que el bipartidismo ya existe. En el otro decimos "crear", con lo que damos por supuesto que partimos de una situación multipartidista que quisiéramos reconvertir en bipartidismo. En el primer caso, es probable que un sistema mayoritario funcione como se espera de él, es decir que mantenga el status quo e impida la proliferación de partidos. Pero en el segundo, no: el cambio de la representación proporcional al sistema mayoritario no se traducirá con toda probabilidad en una réducción del número de partidos.

Lo expuesto requiere cierta explicación. En principio debería quedar claro que el sistema de circunscripción uninominal impone a los votantes la alternativa entre dos partidos sólo sobre la base de la circunscripción electoral, es decir, distrito por distrito. De ahí que un sistema bipartidista a escala nacional asuma que los principales contendientes en todos los distritos son los mismos dos partidos. Otra condición adicional es que el apoyo a un tercer partido se distribuya de manera normal, o dispersa (como en el caso del partido liberal en Inglaterra) por todas las circunscripciones. Esto significa que si el apoyo al tercer partido se concentra en áreas concretas a niveles de mayoría, el sistema electoral no producirá una configuración nacional bipartidista, sino que tendrá que contar con tanto partidos adicionales como dicten las concentraciones de minorías. Por lo tanto, el "límite" aquí es que la ingeniería electoral no puede, sola por sí misma, producir un sistema bipartidista a menos que se den determinadas condiciones previas.

Examinemos a continuación el segundo supuesto, el cambio desde el multipartidismo al bipartidismo. Como ya he apuntado, en este caso un mero sistema de mayoría lograría muy poco y fracasaría en sus propósitos reduccionistas. En la reciente experiencia italiana (en las elecciones generales de 1994 y 1996) la introducción del sistema mayoritario no disminuyó, sino que se tradujo en un aumento del número de partidos relevantes. Lo cual se debe a que en un sistema en el que el ganador

6. Véase al respecto mi Ingeniería constitucional comparada, antes citada, en particular las páginas 55-65 y 84-85. 
se lo lleva todo, los partidos medianos, e incluso los pequeños que estén consolidados por un pre-existente modelo multipartidista, adquieren un poder formidable de chantaje. Con las elecciones mayoritarias los partidos pequeños no pueden por sí mismos lograr escaños, pero si pueden convertir a un posible ganador en perdedor. Supongamos que las "victorias" de la mayoría se alcanzan -con cuatro o seis candidatos por distrito- con un 35\% de los votos y que muchas de las contiendas resultan reñidas. En esas circunstancias incluso un partido pequeño con un $2 \%$ de los votos puede chantajear a los contendientes más importantes con el siguiente mensaje: $\mathrm{o}$ apoyáis a mis candidatos en un determinado número de distritos o presentaré a mis candidatos dondequiera que puedan perjudicar a los vuestros. El argumento es contundente. A decir verdad, gracias al mismo varios partidos italianos han logrado sobrevivir eludiendo las consecuencia del sistema electoral mayoritario.

Podría parecer que lo anterior equivale a un severo golpe a la ingeniería de los sistemas de partidos. Si incluso las elecciones mayoritarias pueden fracasar a la hora de reducir el número de partidos, entonces ¿qué? Bien, es muy posible que lo que unas elecciones del tipo inglés no consigan, se pueda lograr mediante el sistema francés de doble vuelta (reforzado con el establecimiento de un tope elevado para ser admitido al desempate).

Con la doble vuelta, en la primera los votantes son tan libres como con el sistema de representación proporcional (expresan su preferencia en términos de una "Votación sincera"), pero en la segunda los partidos pequeños han desaparecido, es decir, han perdido su poder de chantaje, y el sistema electoral mayoritario puede desplegar su efectos reductores. En la experiencia francesa, el modelo altamente fragmentado de la Cuarta República se ha visto gradualmente comprimido desde los años 1960 hasta convertirse en un cuarteto bipolar (es decir, dos contra dos partidos mayoritarios) y presenta ahora una configuración tripartidista. Y aunque puede argumentarse que la doble vuelta no es la única causa de esta transformación, el éxito de la Quinta República debe mucho a su sistema electoral.

El resultado de toda esta discusión es que mientras el ingeniero político está lejos de ser omnipotente, no es tan impotente como se nos decía y mucho menos tan incapaz de predicciones. Los límites de la ingeniería constitucional están establecidos, caso por caso, por el análisis de las condiciones, es decir, por la pregunta ¿bajo que condiciones podrá cualquier intervención específica, cualquier instrumento concreto, producir el efecto perseguido?

Ahora bien, es cierto que las condiciones en cuestión escapan a menudo de la manipulación deliberada. Ello no obstante, cuando el análisis de las condiciones revela que determinado curso de acción resultará ineficaz, la solución se encuentra en la búsqueda de vías alternativas. En nuestro ejemplo anterior, lo que un sistema de mayoría a una sola vuelta no puede lograr, puede hacerlo el sistema de doble vuelta. Y aún hay más. Supongamos que el análisis de las condiciones revela que, bajo las condiciones existentes, y hasta cierto punto difíciles, cierto sistema político no puede funcionar. Por ejemplo, puede darse el caso de que dadas las condiciones existentes no puede funcionar el sistema presidencial; el análisis nos indicaría las alternativas y opciones factibles en un país que pretende abandonar el presidencialismo. Pensemos en Brasil, que recientemente sometió a 
referéndum si debía transformar su sistema presidencial en uno parlamentario. Por fortuna, en mi opinión, la propuesta fue rechazada, pues el análisis de las condiciones revelaba con claridad que Brasil carece de la base necesaria para que funcione adecuadamente un sistema parlamentario.

Curiosamente mientras a Brasil se le aconseja que abandone el presidencialismo, a Italia que haga lo propio con el parlamentarismo. La sugerencia inicial era que el sistema presidencial sería la mejor cura para los males italianos. Sin embargo, la opinión de los expertos en general ha apuntado que la única opción factible en términos aplicabilidad (el éxito de un trasplante constitucional) se encontraba no en la forma presidencial norteamericana, sino en la semi-presidencial francesa. En fébrero de 1996 se alcanzó un acuerdo entre los partidos principales en ese sentido que no llegó a materializarse (con el intento del gobierno Maccanico) por muy poco. Y aunque con los políticos nunca se sabe, es cierto que el análisis de las condiciones jugó un papel central durante el debate constitucional italiano.

De modo que la ingeniería constitucional no es un Leviathan. Pero no deberíamos elaborar constituciones, como lo estamos haciendo, en la obscuridad y sin su ayuda. Al menos, la ingeniería constitucional nos advierte sobre los "imposibles" y, por la misma razón, nos conduce a buscar los "posibles".

Y para concluir voy a situar mi análisis en perspectiva. Como dije al principio, mi enfoque se centra en la gobernabilidad, en procurar una gobernación democrática, dotada con capacidades efectivas de gobierno. En términos negativos, se trata de "evitar la parálisis", de superar el gobierno encadenado.

Soy consciente, empero, del hecho de que el gobierno representativo tiene también que "representar" y de que, para mucha gente, la preocupación principal es que exista una representación justa e igualitaria, la distribución de escaños "en proporción " a los votos. Y sería magnífico que pudieran maximizarse las dos exigencias del gobierno representativo, la gobernación y la representación. La verdad es, sin embargo, que aquí nos encontramos ante una suerte de transacción. Tenemos, o bien que sacrificar la representatividad del parlamento a la necesidad de gobierno eficaz (la solución inglesa), o bien que sacrificar la función del funcionamiento a la función de reflejo (la solución del consenso-consociacional explorada por Arend Lipjhart). Por lo tanto, a lo largo de esta exposición he ignorado en parte el problema de la representatividad, no porque no tenga conciencia del mismo, sino porque he asumido que la gobernabilidad es, en nuestras sociedades, la prioridad de nuestro tiempo. 